\title{
Ventilatory management of patients on ECMO
}

\author{
Sarvesh Pal Singh ${ }^{1}$ (D) Milind Padmakar Hote ${ }^{1}$
}

Received: 14 October 2019 / Revised: 16 July 2020 / Accepted: 22 July 2020 / Published online: 12 August 2020

(C) Indian Association of Cardiovascular-Thoracic Surgeons 2020

\begin{abstract}
Extracorporeal membrane oxygenation (ECMO) is the final treatment offered to patients of acute respiratory distress syndrome (ARDS). The survival (to discharge) of patients on veno-venous ECMO is approximately $59 \%$ with an average duration of 8 days. The ventilatory management of lungs during the ECMO may have an impact on mortality. An ideal ventilation modality should promote recovery, prevent further damage to the alveoli, and enable weaning from mechanical ventilation. This article reviews the concept of "baby lung" in ARDS and the current evidence for the use of lung protective ventilation, prevention of ventilator-induced lung injury, recommended modes of mechanical ventilation, ideal ventilatory parameters (tidal volume, positive end expiratory pressure, plateau pressure, respiratory rate, fractional inspired oxygen concentration), and use of adjuncts (prone positioning, neuromuscular blocking agents) during the ECMO course.
\end{abstract}

Keywords Ventilation $\cdot$ Extracorporeal $\cdot$ Membrane $\cdot$ Oxygenation $\cdot$ ARDS

\section{Introduction}

Extracorporeal membrane oxygenation (ECMO) is the final treatment offered to patients of acute respiratory distress syndrome (ARDS). As published by the Extracorporeal Life Support Organization (ELSO), the survival (to discharge) of patients on veno-venous ECMO is approximately $59 \%$ with an average duration of 8 days [1]. The initiation of ECMO in ARDS not only improves the gas exchange but also provides rest to the damaged lungs. The ventilatory management of lungs during the ECMO may have an impact on mortality [2-4]. Although a recent study concluded that the mechanical ventilation settings, during ECMO, does not affect the patient prognosis [5], an ideal ventilation modality should promote recovery, prevent further damage to the alveoli, and enable weaning from mechanical ventilation. In a worldwide survey of 141 centers, Marhong et al. reported that the primary goal of ventilation in patients on veno-venous ECMO for ARDS was "lung rest" in $77 \%$ of

Sarvesh Pal Singh

sarveshpal.singh@gmail.com

1 Department of Cardio-Thoracic and Vascular Surgery, Cardio-Thoracic Sciences Center, All India Institute of Medical Sciences, New Delhi 110029, India centers and "lung recruitment" in $9 \%$ of the participating centers. Ninety percent of centers followed a practice of weaning ECMO first [6].

\section{Ventilator-induced lung injury}

Ventilator-induced lung injury (VILI) may be caused by barotrauma, volutrauma, atelectrauma, lung inflammation, oxygen toxicity, and increased mechanical power during ventilation. The various strategies that have improved the outcomes in ARDS patients are limiting the tidal volume (avoiding volutrauma), reducing alveolar pressure (avoiding barotrauma), minimizing cyclical complete collapse and reopening of the alveoli (avoiding atelectrauma), recruitment of the affected lung (using positive end expiratory pressure, PEEP), lower fraction of inspired oxygen $\left(\mathrm{FiO}_{2}\right)$ levels to achieve optimal oxygenation, and preventing increase in mechanical power of ventilation (7-17).

Mechanical power of ventilation per minute is the energy spent per breath multiplied by respiratory rate (RR). The power increases exponentially with the increase in tidal volume, driving pressure of each breath $(\triangle \mathrm{Paw})$, flow, and $\mathrm{RR}$. The mechanical power increases with increase in PEEP [16]. It is an independent risk factor for mortality in the intensive care unit (ICU), ventilator-free days, and duration of ICU and hospital stay [17]. Mechanical power more than $17 \mathrm{~J} / \mathrm{min}$ has 
been associated with risk of death [17]. In the EOLIA (ECMO to Rescue Lung Injury in severe ARDS) trial, a decrease in mechanical power by $66 \%$ ( 28 to $10 \mathrm{~J} / \mathrm{min}$ ) was associated with increased survival $(81 / 124$ vs $68 / 125)$ in patients on veno-venous ECMO $[18,19]$. The EOLIA trial, however, was not designed to study the effect of mechanical power on outcomes of veno-venous ECMO.

\section{"Baby lung" concept in ARDS}

The initial opinion about the status of the lungs in ARDS began to change in the 1980s with the availability of computed tomography (CT) scan images which showed that the lung involvement is heterogenous with areas of normal aeration scattered (with normal elasticity) among the consolidated areas [20]. This "baby lung" was believed to be a structurally normal lung in the non-dependent areas of the lungs. It was established that the total pulmonary compliance, in ARDS patients, was dependent on the compliance of this baby lung. Extracorporeal assistance was only used in patients with respiratory compliance of less than $20 \mathrm{ml} /$ $\mathrm{cm} \mathrm{H}_{2} \mathrm{O}$. However, repeated CT imaging of patients in supine and prone position revealed that the "baby lung" is a functional entity rather a structural entity because the gravity-dependent densities shifted to the new dependent lung zones as soon as the position was changed [21]. Gattitoni et al. explained in their paper that the amount of stress ( $K \times$ strain, where $K$ is Young's modulus) and strain (change in length of fibers of lung skeleton, $\Delta \mathrm{L}$ ) will depend on the size of the baby lung when being ventilated with the same tidal volume of $6 \mathrm{ml} / \mathrm{kg}$ [21]. Therefore, it may be prudent to decide on an individualized tidal volume for each patient rather than using a single value-based calculation (for, e.g., $6 \mathrm{ml} / \mathrm{kg}$ ) for all patients. Also, it is observed that there is an increase in the stress at the junction of open and closed tissues and these junctions often exist in gravity-dependent zones of the lung.

\section{Mechanical ventilation}

\section{Mode of mechanical ventilation}

The options available for the mode of mechanical ventilation in ARDS patients are controlled ventilation, pressure-assisted spontaneous ventilation, airway pressure release ventilation (APRV), and neurally adjusted ventilator assist (NAVA) in combination with ECMO. The preferred initial mode of ventilation during ECMO is controlled (62\%), followed by support $(21 \%)$ and APRV (4\%). NAVA has been reported in occasional case reports and series [6].

\section{Controlled ventilation}

Out of the controlled modes, pressure-controlled mode is the preferred mode of ventilation [22]. Schmidt et al. [23] reported an increase in the utilization of pressure-targeted modes of ventilation pre- and post-ECMO (from 55 to $90 \%$ ). Volumecontrolled mode is used in $50 \%$ of patients prior to ECMO placement but the percentage of pressure-targeted modes increases from $69 \%$ on day 1 to $82 \%$ on day 14 of ECMO [5].

\section{Pressure-assisted spontaneous ventilation}

In pressure support ventilation (PSV), the termination criterion for breath (flow cycled) is constant. This may lead to patient ventilator asynchrony. The work of breathing progressively increases with the increase in the termination criterion from 1 to $45 \%$ of the peak inspiratory flow. It has been observed that setting the threshold to $5 \%$ of the peak inspiratory flow might be the optimal value for patients with acute lung injury (ALI) or ARDS. This may also decrease the patient ventilator asynchrony in ARDS [24]. The termination criterion for breath (at 5\% and $40 \%$ of peak inspiratory flow) has also been studied at different pressure support levels (5 and $15 \mathrm{~cm} \mathrm{H}_{2} \mathrm{O}$ ) in PSV. A 5\% cycling off criterion and a pressure support of $15 \mathrm{~cm} \mathrm{H} 2 \mathrm{O}$ have been shown to reduce the respiratory rate and increased the tidal volume without modifying the work of breathing [25]. In this study, the inspiratory rise time was also studied at $0 \%$ and $40 \%$ of breath cycle time. The shortest inspiratory rise time was associated with reduced work of breathing by more than $50 \%$ [25].

\section{Airway pressure release ventilation}

Airway pressure release ventilation (APRV) is a pressuretargeted mode of ventilation where the patient breathes spontaneously at two different levels of pressure $\left(P_{\text {High }}\right.$ and $\left.P_{\text {Low }}\right)$ with intermittent mandatory breaths. The $P_{\text {High }}$ is applied as continuous positive pressure for a defined duration $\left(T_{\mathrm{High}}\right)$ and only released intermittently up to $P_{\text {Low }}$ for short duration $\left(T_{\text {Low }}\right)$. These releases help in expiration of built-up carbon dioxide during $T_{\mathrm{High}}$. The use of APRV decreases atelectrauma, use of sedation, and neuromuscular blocking agents (NMBAs) requirement, and increases oxygenation and recruitment of the alveoli [26-28]. Early use of APRV in ARDS reduces both duration of mechanical ventilation and ICU stay [29, 30]. Despite its beneficial effects, there are only occasional case series documenting the use of APRV mode during ECMO therapy $[31,32]$. It is possible to achieve ultraprotective tidal volumes (mandatory breaths) and low transpulmonary pressures (spontaneous breaths) with APRV during the ECMO course. One indirect advantage of APRV is preservation of diaphragmatic function due to fewer requirements of NMBAs. 


\section{Neurally adjusted ventilatory assist}

Neurally adjusted ventilatory assist (NAVA) is a closedloop ventilation mode which depends on the electrical activity of the diaphragm (EAdi) to trigger ventilation. The EAdi signal (measured in microvolts) is multiplied by a factor called NAVA level and transposed into pressure support. The description of the use of NAVA on veno-venous ECMO (VV ECMO) is limited to one case series only [33]. The authors (Karagiannidis) were able to achieve protective lung ventilation with NAVA where at a preset PEEP level of 10 or more the mean peak inspiratory pressure (PIP) did not cross $30 \mathrm{~cm} \mathrm{H}_{2} \mathrm{O}$ [33]. The authors also established that the tidal volume (TV) achieved by the patient's own respiratory effort on active ECMO was not more than $6 \mathrm{ml} / \mathrm{kg}$. A cessation of the sweep flow on ECMO (inactive ECMO) caused an immediate increase in the minute ventilation of the patients with tidal volumes of not more than $8 \mathrm{ml} / \mathrm{kg}$. The NAVA mode offers the advantage of regulating TV by the patient (in proportion to EAdi), early establishment of spontaneous breathing, and avoiding disuse atrophy of diaphragm. It has been proved that complete diaphragmatic inactivity and mechanical ventilation for 18-69 h leads to marked atrophy of diaphragmatic fibers in humans [34].

\section{Ventilatory parameters}

\section{Tidal volume}

In an international survey, out of the 141 centers taking part, $31 \%$ used $\leq 4 \mathrm{ml} / \mathrm{kg} \mathrm{TV}, 45 \%$ centers used $4-6 \mathrm{ml} /$ $\mathrm{kg}$ tidal volume, and only $2 \%$ centers reported using 7 $9 \mathrm{ml} / \mathrm{kg}$ TV during mechanical ventilation for patients on respiratory ECMO. The rest $(21 \%)$ of the centers had no strict criteria on usage of fixed TV range [6]. Another study reported a TV of $<6 \mathrm{ml} / \mathrm{kg}$ in $81 \%$ of adult centers, of which $34 \%$ reported using TV below $4 \mathrm{ml} / \mathrm{kg}$ during veno-venous ECMO [22]. A TV $<4 \mathrm{ml} / \mathrm{kg}$ (in comparison with $\mathrm{TV}>4 \mathrm{ml} / \mathrm{kg}$ ) following ECMO initiation is associated with lower mortality as well [4]. In the absence of large randomized studies comparing ultraprotective ventilation ( $\mathrm{TV} \leq 4 \mathrm{ml} / \mathrm{kg}$ ) with protective ventilation (TV $=4-6 \mathrm{ml} / \mathrm{kg}$ ) during the course of ECMO, a definite recommendation cannot be made for the use of TV $<4 \mathrm{ml} / \mathrm{kg}$. A decrease in TV and RR is reported in almost all studies immediately after initiation of ECMO. This decrease in TV decreases driving pressure and mechanical power of ventilation, which is an independent factor for survival.

\section{Positive end expiratory pressure}

As per conventional teaching, decrease in tidal volume and increase in PEEP recruit the functional alveoli and may help in improving gas exchange and decrease airway pressures (ARDS net protocol) [35]. In patients suffering from ARDS and with established ECMO support, $80 \%$ of centers report using PEEP more than $5 \mathrm{~cm} \mathrm{H}_{2} \mathrm{O}\left(58 \%, 6-10 \mathrm{~cm} \mathrm{H}_{2} \mathrm{O}\right.$; and $22 \%,>10 \mathrm{~cm} \mathrm{H}_{2} \mathrm{O}$ ) [6]. The application of "individualized" PEEP mitigates atelectrauma by preventing complete collapse and reopening of the alveoli with each breath. However, there is an increased risk of barotrauma at higher levels of PEEP. If there is no recruitment of the alveoli, with increasing levels of PEEP, there is an increase in the static alveolar strain that may lead to overdistention of the alveoli and an increase in plateau and driving pressures (plateau pressure - PEEP). Exceptionally high levels of PEEP may cause hemodynamic instability due to decrease in venous return. Contrarily, if alveolar recruitment occurs with the application of PEEP, there is a decrease in the plateau and driving pressures. Therefore, instead of using fixed combinations of PEEP and tidal volume, it is desirable to use individualized PEEP settings on the basis of response as measured by objective criteria (plateau and driving pressures).

It is almost impossible to achieve optimal tidal volume in the early period of the VV ECMO. The TV may be as low as $<2 \mathrm{ml} / \mathrm{kg}$ in a setting of high PEEP. Animal studies have shown that high PEEP (in patients with very low tidal volume) may achieve convective ventilation and prevent atelectasis during apneic oxygenation on ECMO support [36]. It may, however, lead to alveolar distension and hemodynamic compromise.

Positron emission tomography (PET) scans had shown that although baby lung has a near-normal compliance it still displays greater inflammatory activity than collapsed nonaerated lung areas as measured by pulmonary transcapillary escape rate [37]. The use of PEEP during ECMO has been shown to decrease the inflammation in the baby lung (38-40).

\section{Plateau pressure}

During mechanical ventilation on ECMO, it is desirable to achieve a plateau pressure (Pplat) less than $30 \mathrm{~cm} \mathrm{H}_{2} \mathrm{O}$ and preferable to keep it below $25 \mathrm{~cm} \mathrm{H}_{2} \mathrm{O}$. Higher values of Pplat ( 29 vs $25 \mathrm{~cm} \mathrm{H}_{2} \mathrm{O}$ ) on day 1 of ECMO have been associated with ICU death [40]. In a systematic review of 49 studies of veno-venous ECMO, lower plateau pressures (19-22 vs 31$36 \mathrm{~cm} \mathrm{H}_{2} \mathrm{O}$ ) were associated with less mortality (28\% vs $46 \%$ ). The lowest mortality was observed in studies reporting a combination of low plateau pressures $\left(\leq 26 \mathrm{~cm} \mathrm{H}_{2} \mathrm{O}\right)$ and low tidal volumes $(\leq 4 \mathrm{ml} / \mathrm{kg}$ ) [4]. An increase in Pplat by $1 \mathrm{~cm} \mathrm{H}_{2} \mathrm{O}$ in patients on ECMO decreases the odds of hospital survival by $21 \%$ [41]. 


\section{Fractional inspired oxygen concentration and respiratory rate}

With sufficient oxygenation provided by ECMO, it is advisable to reduce $\mathrm{FiO}_{2}$ levels to less than $40 \%$ to reduce toxic effects of oxygen on lungs [4]. It may not be possible in all patients; therefore, a strategy to minimize the $\mathrm{FiO}_{2}$ to maximum while maintaining arterial oxygen saturation levels between 85 and $90 \%$ is acceptable. At our institute, the practice is to keep $100 \% \mathrm{FiO}_{2}$ on ECMO at the time of initiation and gradually decrease the $\mathrm{FiO}_{2}$ on ventilator $<40 \%$ while attaining a target $\mathrm{SpO}_{2}$ (peripheral oxygen saturation) of $85 \%$. During the course of ECMO, a decrease of $\mathrm{FiO}_{2}$ on membrane oxygenator is also attempted with the same saturation target. The low $\mathrm{FiO}_{2}$ to the lungs decreases the possibility of absorption atelectasis and oxygen-free radical injury [42]. There is no universal consensus on respiratory rate values during veno-venous ECMO. Although the ELSO guidelines recommend a $R R$ as low as $5 / \mathrm{min}$, various studies have quoted RR between 5 and 30 breaths per minute $[18,40,43]$.

\section{Adjuncts to mechanical ventilation on ECMO}

Neuromuscular blockers and prone positioning are the two most commonly used adjuncts during ECMO therapy.

\section{Prone positioning}

The use of prone positioning and lung protective ventilation in patients with ARDS leads to significant reduction in mortality [44]. The use of prone position during ECMO course is fraught with the possibility of complications (bleeding and mechanical). Kimmoun et al. in their study of 17 patients with 27 sessions of proning reported no serious adverse events [45]. There was an increase in $\mathrm{PaO}_{2}$ (partial pressure of oxygen in arterial blood) $/ \mathrm{FiO}_{2}$ ratio by $20 \%$ in all patients who were proned after 7 days of ECMO and in 50\% patients who were proned within 7 days of ECMO initiation [45]. The complications of prone positioning during ECMO are bleeding (10-13\%), edema $(12.2 \%)$, hemodynamic instability $(9.5 \%)$, air entrainment in the ECMO circuit $(2.0 \%)$, and pneumothorax $(2.0 \%)$ [46]. In terms of severity, neither of these complications is serious except for occasional patients. Therefore, it is only reasonable to assume that prone ventilation during ECMO can be used to improve oxygenation status with an acceptable complication risk. A recent study has shown an increase in utilization of prone position during course of ECMO by $42 \%$ [47].

\section{Neuromuscular blocking agents}

The incidence of NMBA usage during ECMO varies from 12.6 to $58.2 \%[47,48]$. Current evidence shows no survival benefit with the use of NMBA in patients with ARDS [49]. However, the use of NMBA in ARDS prevents patient ventilator asynchrony and improves oxygenation. Therefore, it is not uncommon to use NMBA in the initial $24-48 \mathrm{~h}$ after commencing ECMO support. The prolonged use of NMBA may cause impaired diaphragmatic function and is a risk factor for critical illness myopathy as well [34].

\section{Extracorporeal carbon dioxide removal}

The approximate carbon dioxide $\left(\mathrm{CO}_{2}\right)$ production per minute in an average adult is $250 \mathrm{ml} / \mathrm{min}$. The content of carbon dioxide in venous blood is $52 \mathrm{ml} / \mathrm{min}$. Therefore, an estimated flow of $500 \mathrm{ml} / \mathrm{min}$ during ECMO is sufficient to remove $\mathrm{CO}_{2}$ from the body. The requirement of such low flows during extracorporeal carbon dioxide removal $\left(\mathrm{ECCO}_{2} \mathrm{R}\right)$ obviates the need of a pump so that the membrane lung is connected to the arterial and venous cannulae directly. This rapid removal of $\mathrm{CO}_{2}$ allows a decrease in the minute ventilation by decreasing the RR and TV both, thus decreasing Pplat and enabling protective ventilation [22]. In patients undergoing mechanical ventilation for ARDS, the use of extracorporeal $\mathrm{CO}_{2}$ removal helps in decreasing the driving pressure (Pplat - PEEP) by achieving low tidal volume of $3 \mathrm{ml} / \mathrm{kg}$ in comparison with $6 \mathrm{ml} / \mathrm{kg}$ with conventional lung protective ventilation [50].

\section{Ventilatory protocol for veno-venous ECMO at our center}

Once the full flows on ECMO have been established, the lungs are ventilated with a volume-controlled mode. The initial settings are as follows: TV of $3-4 \mathrm{ml} / \mathrm{kg}, \mathrm{FiO}_{2}$ on ventilator $100 \%$, PEEP $12-15 \mathrm{~cm} \mathrm{H}_{2} \mathrm{O}$, inspiratory:expiratory (I:E) ratio $1: 1.5$ to $1: 2.0$, and $\mathrm{RR} 10 / \mathrm{min}$. The $\mathrm{FiO}_{2}$ is decreased to $<40 \%$ once the $\mathrm{PaO}_{2}$ (in successive blood gas reports) stabilizes. Packed red blood cell transfusion is done to improve oxygen delivery by increasing the hematocrit to more than $36 \%$. The Pplat is maintained at a level of less than $25 \mathrm{~cm}$ $\mathrm{H}_{2} \mathrm{O}$. If the Pplat is $>25 \mathrm{~cm} \mathrm{H}_{2} \mathrm{O}, \mathrm{RR}$ and TV are further reduced to reach the target of $25 \mathrm{~cm} \mathrm{H}_{2} \mathrm{O}$. In patients where the lung compliance is abysmal, or later during the ECMO run, a switch from volume to pressure control mode is often made to maintain peak airway pressures less than $40 \mathrm{~cm} \mathrm{H}_{2} \mathrm{O}$. In arterial blood gas analysis, the following targets are followed: $\mathrm{pH}$ 7.3-7.4; $\mathrm{PaO}_{2}, 50-60 \mathrm{mmHg} ; \mathrm{SaO}_{2}$ (oxygen saturation), $80-90 \%$; $\mathrm{PaCO}_{2}$ (partial pressure of carbon dioxide in arterial blood), $35-40 \mathrm{mmHg}$, and hematocrit $36-40 \%$. 
For the first $24-48 \mathrm{~h}$, the patient is kept sedated and paralyzed, and then a "sedation-only" strategy is followed for another 24-48 h. A policy of "intermittent sedation" is followed after $96 \mathrm{~h}$ of ECMO initiation. After 3-4 days of ECMO, when the patient is on the sedation-only regimen, the ventilatory mode is switched to synchronized intermittent mandatory ventilation (SIMV) with pressure support for spontaneous breaths. In this mode, we choose pressure support between 10 and $15 \mathrm{~cm} \mathrm{H}_{2} \mathrm{O}$, a negative pressure trigger of 2 to $3 \mathrm{~cm} \mathrm{H}_{2} \mathrm{O}$ for spontaneous breaths, an expiratory trigger of $25 \%$ of peak inspiratory flow, and an inspiratory rise time of $5 \%$ of breath cycle time. However, this is only possible in patients who begin improving, after 4-5 days, on ECMO. Patients who do not show improvement within the first 4-5 days are very irritable (e.g., non-resolving sepsis), and the sedation-only strategy duration gets prolonged until 5-7 days. Such non-improving patients are maintained on volume-controlled ventilation only.

\section{Conclusions}

The use of extracorporeal support in patients with ARDS is increasing because it helps in achieving protective and ultraprotective ventilation of lungs. There is no conclusive evidence to recommend one mode of mechanical ventilation over another. A decrease in mechanical power of ventilation seems to have a beneficiary effect on outcomes. A low ventilation driving pressure $\left(<15 \mathrm{~cm} \mathrm{H}_{2} \mathrm{O}\right)$ and tidal volume $(<4 \mathrm{ml} / \mathrm{kg})$ are associated with better survival. Prone position and NMBAs can be safely used for better oxygenation and patient-ventilator synchrony, respectively. In the era of precision medicine, it is desirable to have personalized ventilatory settings for every patient to minimize ventilator-induced lung injury.

\section{Funding None.}

\section{Compliance with ethical standards}

Conflict of interest The authors declare that they have no conflict of interest.

Ethical approval Not applicable being a review article.

Informed consent Not applicable being a review article.

Statement of Human and Animal rights Not Applicable being a review article.

\section{References}

1. ECLS Registry. The international summary -July 2019. https:// www.elso.org/Registry/Statistics/InternationalSummary.aspx. (last accessed 11 October 2019).
2. Schmidt M, Pellegrino V, Combes A, Scheinkestel C, Cooper DJ, Hodgson C. Mechanical ventilation during extracorporeal membrane oxygenation. Crit Care. 2014;18:203.

3. Frank JA, Gutierrez JA, Jones KD, Allen L, Dobbs L, Matthay MA. Low tidal volume reduces epithelial and endothelial injury in acidinjured rat lungs. Am J Respir Crit Care Med. 2002;165:242-9.

4. Marhong JD, Munshi L, Detsky M, Telesnicki T, Fan E. Mechanical ventilation during extracorporeal life support (ECLS): a systematic review. Intensive Care Med. 2015;41:994-1003.

5. Schmidt M, Pham T, Arcadipane A, et al. Mechanical ventilation management during Extracorporeal Membrane Oxygenation for Acute Respiratory Distress Syndrome: An International Multicenter Prospective Cohort. Am J Respir Crit Care Med.2019;200:1002-12.

6. Marhong JD, Telesnicki T, Munshi L, Sorbo LD, Detsky M, Fan E. Mechanical ventilation during extracorporeal membrane oxygenation an international survey. Ann Am Thorac Soc. 2014;11:956-61.

7. Tremblay LN, Slutsky AS. Ventilator-induced injury: from barotrauma to biotrauma. Proc Assoc Am Physicians. 1998;110:482-8.

8. Tonetti T, Vasques F, Rapetti F, et al. Driving pressure and mechanical power: new targets for VILI prevention. Ann Transl Med. 2017;5:286.

9. Amato MBP, Meade MO, Slutsky AS, et al. Driving pressure and survival in the acute respiratory distress syndrome. N Engl J Med. 2015;372:747-55.

10. Protti A, Andreis DT, Monti M, et al. Lung stress and strain during mechanical ventilation: any difference between statics and dynamics? Crit Care Med. 2013;41:1046-55.

11. Chiumello D, Carlesso E, Cadringher P, et al. Lung stress and strain during mechanical ventilation for acute respiratory distress syndrome. Am J Respir Crit Care Med. 2008;178:346-55.

12. Ranieri VM, Giunta F, Suter PM, Slutsky AS. Mechanical ventilation as a mediator of multisystem organ failure in acute respiratory distress syndrome. JAMA. 2000;284:43-4.

13. Parsons PE, Eisner MD, Thompson BT, et al. Lower tidal volume ventilation and plasma cytokine markers of inflammation in patients with acute lung injury. Crit Care Med. 2005;33:1-6.

14. Munshi L, Kiss A, Cypel M, Keshavjee S, Ferguson ND, Fan E. Oxygen thresholds and mortality during extracorporeal life support in adult patients. Crit Care Med. 2017;45:1997-2005.

15. Cashen K, Reeder R, Dalton HJ, et al. Hyperoxia and hypocapnia during pediatric extracorporeal membrane oxygenation: associations with complications, mortality, and functional status among survivors. Pediatr Crit Care Med. 2018;19:245-53.

16. Gattinoni L, Tonetti T, Cressoni M, et al. Ventilator-related causes of lung injury: the mechanical power. Intensive Care Med. 2016;42: 1567-75.

17. Serpa Neto A, Deliberato RO, Johnson AEW, et al. Mechanical power of ventilation is associated with mortality in critically ill patients: an analysis of patients in two observational cohorts. Intensive Care Med. 2018;44:1914-22.

18. Combes A, Hajage D, Capellier G, et al. Extracorporeal membrane oxygenation for severe acute respiratory distress syndrome. N Engl J Med. 2018;378:1965-75.

19. Gattinoni L, Vasques F, Quintel M. Use of ECMO in ARDS: does the EOLIA trial really help? Crit Care. 2018;22:171.

20. Gattitoni L, Pesenti A, Avalli L, Rossi F, Bombino M. Pressure volume curve of total respiratory system in acute respiratory failure. A computed tomographic scan study. Am Rev Respir Dis. 1987;136:730-6.

21. Gattinoni L, Pesenti A. The concept of "baby lung". Intensive Care Med. 2005;31:776-84.

22. Patroniti N, Bonatti G, Senussi T, Robba C. Mechanical ventilation and respiratory monitoring during extracorporeal membrane oxygenation for respiratory support. Ann Transl Med. 2018;6:386. 
23. Schmidt M, Stewart C, Bailey M, et al. Mechanical ventilation management during extracorporeal membrane oxygenation for acute respiratory distress syndrome: a retrospective international multicenter study. Crit Care Med. 2015;43:654-64.

24. Tokioka $\mathrm{H}$, Tanaka $\mathrm{T}$, Ishizu $\mathrm{T}$, et al. The effect of breath termination criterion on breathing patterns and the work of breathing during pressure support ventilation. Anesth Analg. 2001;92:161-5.

25. Chiumello D, Pelosi P, Taccone P, Slutsky A, Gattinoni L. Effect of different inspiratory rise time and cycling off criteria during pressure support ventilation in patients recovering from acute lung injury. Crit Care Med. 2003;31:2604-10.

26. Habashi NM. Other approaches to open-lung ventilation: airway pressure release ventilation. Crit Care Med. 2005;33:S228-40.

27. Modrykamien A, Chatburn RL, Ashton RW. Airway pressure release ventilation: an alternative mode of mechanical ventilation in acute respiratory distress syndrome. Cleve Clin J Med. 2011;78: 101-10.

28. Wrigge $\mathrm{H}$, Zinserling J, Neumann $\mathrm{P}$, et al. Spontaneous breathing with airway pressure release ventilation favors ventilation in dependent lung regions and counters cyclic alveolar collapse in oleic-acid induced lung injury: a randomized controlled computed tomography trial. Crit Care. 2005;9:R780-9.

29. Zhou Y, Jin X, Lv Y, et al. Early application of airway pressure release ventilation may reduce the duration of mechanical ventilation in acute respiratory distress syndrome. Intensive Care Med. 2017;43:1648-59.

30. Putensen C, Zech S, Wrigge H, et al. Long -term effects of spontaneous breathing during ventilatory support in patients with acute lung injury. Am J Respir Crit Care Med. 2001;164:43-9.

31. Roze H, Richard JCM, Thumerel M, Ouattara A. Spontaneous breathing (SB) using airway pressure release ventilation (APRV) in patients under extracorporeal -membrane oxygenation (ECMO) for acute respiratory distress syndrome (ARDS). Intensive care Med. 2017;43:1919-1920

32. Ali N, Patel K, Nazir H, Anadarangam T. Management of severe ARDS with extracorporeal membrane oxygenation and airway pressure release ventilation- a case series. Am J Respir Crit Care. 2015;191:A 4574.

33. Karagiannidis C, Lubnow M, Philipp A, et al. Autoregulation of ventilation with neurally adjusted ventilatory assist on extracorporeal lung support. Intensive Care Med. 2010;36:2038-44.

34. Levine S, Nguyen T, Taylor N, et al. Rapid disuse atrophy of diaphragm fibers in mechanically ventilated humans. N Engl J Med. 2008:358:1327-35.

35. NIH NHLBI ARDS Clinical Network. Mechanical ventilation protocol summary http://www.ardsnet.org/files/ventilator_protocol_ 2008-07.pdf. [last accessed 10 October 2019].

36. Nielsen ND, Kjaergaard B, Koefoed-Nielsen J, Steensen CO, Larsson A. Apneic oxygenation combined with extracorporeal arteriovenous carbon dioxide removal provides sufficient gas exchange in experimental lung injury. ASAIO J. 2008;54:401-5.

37. Kaplan JD, Calandrino FS, Schuster DP. A positron emission tomographic comparison of pulmonary vascular permeability during the adult respiratory distress syndrome and pneumonia. Am Rev Respir Dis. 1991;143:150-4.
38. Carpenter TC, Stenmark KR. Hypoxia decreases lung neprilysin expression and increases pulmonary vascular leak. Am J Phys Lung Cell Mol Phys. 2001;281:L941-8.

39. Madjdpour C, Jewell UR, Kneller S, et al. Decreased alveolar oxygen induces lung inflammation. Am J Phys Lung Cell Mol Phys. 2003;284:L360-7.

40. Pham T, Combes A, Roze H, et al. Extracorporeal membrane oxygenation for pandemic influenza A (H1N1)-induced acute respiratory distress syndrome - a cohort study and propensity matched analysis. Am J Respir Crit Care Med. 2013;187:276-85.

41. Modrykamien AM, Hernandez OO, Im Y, et al. Mechanical ventilation in patients with the acute respiratory distress syndrome and treated with extracorporeal membrane oxygenation: impact on hospital and 30 day post discharge survival. ASAIO J. 2016;62:60712.

42. Gattinoni L, Tonetti T, Quintel M. How best to set the ventilator on extracorporeal membrane lung oxygenation. Curr Opin Crit Care. 2017;23:66-72.

43. Peek GJ, Mugford M, Tiruvoipati R, et al. Efficacy and economic assessment of conventional ventilatory support versus extracorporeal membrane oxygenation for severe adult respiratory failure (CESAR): a multicentre randomized controlled trial. Lancet. 2009;374:1351-63.

44. Aoyama H, Uchida K, Aoyama K, et al. Assessment of therapeutic interventions and lung protective ventilation in patients with moderate to severe acute respiratory distress syndrome: a systematic review and network meta-analysis. JAMA Netw Open. 2019;2: e198116.

45. Kimmoun A, Roche S, Bridey C, et al. Prolonged prone positioning under VV-ECMO is safe and improves oxygenation and respiratory compliance. Ann Intensive Care. 2015;5:35.

46. Culbreth RE, Goodfellow LT. Complications of prone positioning during extracorporeal membrane oxygenation for respiratory failure: a systematic review. Respir Care. 2016;61:249-54.

47. Baek MS, Lee SM, Chung CR, et al. Improvement in the survival rates of extracorporeal membrane oxygenation-supported respiratory failure patients: a multicenter retrospective study in Korean patients. Crit Care. 2019;23:1.

48. DeGrado JR, Hohlfelder B, Ritchie BM, Anger KE, Reardon DP, Weinhouse GL. Evaluation of sedatives, analgesics, and neuromuscular blocking agents in adults receiving extracorporeal membrane oxygenation. J Crit Care. 2017;37:1-6.

49. Heart N, Lung, and Blood Institute PETAL Clinical Trials Network, Moss M, Huang DT, Brower RG, Ferguson ND, et al. Early neuromuscular blockade in the acute respiratory distress syndrome. N Engl J Med. 2019;380:1997-2008.

50. Bein T, Weber-Carstens S, Goldmann A, et al. Lower tidal volume strategy (approximately $3 \mathrm{ml} / \mathrm{kg}$ ) combined with extracorporeal $\mathrm{CO} 2$ removal versus 'conventional' protective ventilation $(6 \mathrm{ml} /$ $\mathrm{kg}$ ) in severe ARDS: the prospective randomized Xtravent-study. Intensive Care Med. 2013;39:847-56.

Publisher's note Springer Nature remains neutral with regard to jurisdictional claims in published maps and institutional affiliations. 